\title{
A paradoxical academic life: what we can learn from having the 'end' in sight
}

\begin{abstract}
The ending of a story provides clarity by framing separate encounters within an overall plot. It can intensify focus and feeling, as limited time creates a sense of preciousness. The end additionally calls for new beginnings, as places are vacated for other stories to be told. It is a generative space as new conversations can evolve. The 'end' of an academic story contains opportunities for beginnings and vibrant encounters, and academics may be able to explore the richness within an expansive and generative spaces by having the 'end in sight.'
\end{abstract}

Key words: Aging, academic identity, writing as inquiry

\section{Buried by the sands of time}

We have not here a lasting city, we are told, and reason tells us that. But we pave our cities as if we will promenade their streets forever (Keneally, 2018, para. 21).

"Being-toward-death" is the defining quality of human existence (Heidegger, 1962, as cited in Thomas, 1995, p.22).

"We embody different ages as we travel through life. And we do this with others, with one arm stretched out to those who are older than ourselves, and the other reaching back to those who will follow in our footsteps (Andrews, 2018, p. 94).

"When your future is spoken of in terms of months, things become clearer," a senior colleague remarks. He had recently recovered from a long bout of illness and was considering retirement. I pause for a moment and try to explain how much he will be missed, but he replies without skipping a beat, "No one will notice I am gone." Pelias (2016) expresses similar sentiments as he imagines that his carefully built career will be buried by 'what' comes to take its place, as, "Some younger body is always there, ready to step in, ready to keep culture going" (p. 29). Carpenter equally recollects how her traces were erased only a week after resigning, writing, "I still feel in my bones the jolt of . . . discovering that my photo had already been removed" (emerald \& Carpenter, 2014, p. 1143). These retirees' poignant reflections reveal the fate that awaits us, as ". .. old age is something that all people have the potential to eventually attain" (emerald \& Carpenter, 2014, p. 1142). I find myself struggling with this conundrum of retirement. Although I am not yet at retirement age, I sense the paradox of investing myself so heavily in work that has an expiration date. Richardson affirms how retiring academics may feel lost as much of their lives have been entwined in their profession, acknowledging, "Their work, their friends, and even their vacations-often tied to their disciplines' scholarly meetings-are integrated" (2014, p. 1134). Her comment leads me to ask, if an academic's identity is highly embedded with their professional work, what happens to this identity once the professional role is gone?

The sense of loss incurred through retirement may feel particularly challenging for academics due to the "identity, status, and perks" of their role, where "You pass as smart, even if you aren't; you can claim to know more than you do, and others accept the sham ..." (Richardson, 2014, p. 1133). Academics receive an institutionalised form of acknowledgement that is "clad in regalia of professional rank, professional office, publication in peer-reviewed journals, and various valorous recognitions" (Hendricks, 2008, p.110); this heavily contrasts against the negativity of old age and retirement, which denotes the loss of growth, functionality and purpose (Pelias, 2016; Richardson, 2014; Badley, 2016; Cruikshank, 2008). Retired academics may accordingly struggle with negative associations, such as, ". . worn out. Tired. Outdated. Broken. Useless"(Richardson, 2014, p. 1135). There is also the loss of mentally engaging work and professional collegiality (Pelias, 2016) and the potential loss of self, as one retiree writes, "... when we cease to work, whether caused by dismissal, resignation, health issues, or retirement, we lose a large part of our humanity in the bargain" (Frentz, 2011, p. 799). Retirement can additionally trigger suffering as retirees are 
no longer engaged in the paid work that attributes them with a positive sense of identity (Medeiros, 2009), and even though they may actively volunteer, their efforts may be devalued as one's earning capacity acts as a social marker of a person's usefulness (Richardson, 2014). With these negative implications surrounding retirement, Dowd (2012) asks, "What then do we- those of us who are no longer young- do with our desires to be part of something, to make history, to be attractive to others, and to be someone others wish to know better" (p.287)?

This question comes to mind as I observe a rich kaleidoscope of emotions on the faces of my retiring colleagues who leave their much-coveted tenured posts. Noticing their exuberance at being able to spend time on 'slower' and more intrinsically pleasurable tasks, makes me eager to experience such joy work all throughout my career. Their doubts over the legacy they leave behind, has me pondering what it means to invest myself so deeply in my profession. And finally, the uncertainty they express over the unknown makes me wonder whether living with the 'end in sight' can help to navigate the change and loss that will inevitably come. Like Hendricks (2008), I grapple with the question, "How do we integrate what we know with how we live? It is a question that goes into the very heart of our scholarly endeavours; do we separate personal life from professional life?" (p. 109) I seek to uncover the kind of academic work that will help me thrive throughout my professional and personal life. Manheimer (2008) describes a similar affinity he feels with the elderly, which leads him to teach philosophy at a senior centre. He confesses the reason for his interest, stating:

They were closer to death than, I assumed, I was, and I loved death - the death that Socrates says the philosopher seeks, in which your soul loosens the bonds of the finite and temporal body and escapes to a netherworld where the immortal greats gather to discuss the mysteries that had previously eluded them. The senior center would be my subterranean domain, its inhabitants, my fellow immortals in training (p. 178).

Can the retirement phase hold the secrets to a fulfilling professional life? Randall (2008) suggests this possibility, as the stories of older generations are often " . . undertold and under-read its store of insight squandered, like a book on which its author has labored lovingly for years, only to languish forgotten on the shelf" (p. 171). He reminds us that the stories of retirees need to be told to prevent the loss of a lifetime's worth of wisdom. Bochner highlights the potential of intergenerational stories as he relates how younger academics can learn from retired scholars who write (Ellis et al., 2017), whilst Rivero describes how she looks to the experiences of older women to imagine new ways of aging well in academia (d'Araújo, Alpuim, CaRivero \& Marujo, 2016, p.121). Models can help us to find a path forward they "serve as proxies we scrutinize as guides for our own actions and perhaps too, as templates for possible selves... This is the very core of reflexivity" (Hendricks, 1992, p.3). I am equally drawn to the literature of retired academics as I seek models to follow. I have finally reached the academic summit of tenure after almost a decade of toil. I thought that the pace would slow after reaching the summit. I had not anticipated that it would speed up. Knowing that academia rewards those who climb the most peaks and travel along the fastest track, I find myself contemplating whether to follow this academic narrative of a runaway train careening out of control (Ellis, 2011). The pressure to board overwhelms, and yet I fear that the train's momentum will carry me mindlessly into the future.

\section{Getting lost in academia}

At the entry of the School's office is a locked glass cabinet that contains yellowing and curling photographs of senior academic staff. The photos were taken decades earlier, and so the faces looking out are still in the bloom of youth, with their ruddy cheeks and the rich colour of their hair. I see these smiling faces, and I realise that my senior colleagues with well-established careers, were once unsure, fresh-faced and full of excitement. Their faces are pale and their bodies are now less 
supple due to the years of sitting at a desk, and their energy has become calmer and more contemplative, as they entertain thoughts of retirement.

The 'busy' work of generating publications, grants, promotions and awards can make academics lose sight of all else. Richardson describes this narrowing of perspective as losing one's way in the woods, as she reflects, "That's what university life was like for me. I was, 'into the woods' almost all of the time. . So leaving the university became an out-of-the woods very positive experience for me" (Ellis et al., 2017, p. 579). Academics can lose perspective as they are socialised to uphold the image of the 'good' worker who toils endlessly to "accumulate grants, publications, and patents, as well as to improve teaching evaluations, and structure service commitments" (Shahjahan, 2015, p. 492). This archetype of the 'good' academic equates self-worth with levels of performativity and can lead to workaholism (Boje \& Tyler, 2009). Ellis explains how academics can succumb to workaholism as their workload is unclear and ill-defined; there is never an end to what can be accomplished. She relates how academics can quickly fall into existence, where they wake up each day feeling restless, with a "mind enumerate[ing] and mak[ing] lists nonstop, flipping from topic to topic without any resolution" (Ellis, 2008, p.159). Boje describes the dissatisfaction that drives built into a successful academic career as he finds himself doing even more work even after breaking " . . the hundred published journal article mark [he] had set for [him]self" (Boje \& Tyler, 2009, p. 178). He critiques the seductive nature of academia's reward system that awards points for each output, where the more points collected, the faster one's progression through the academic ranks. Such a life is often attained through solitary evenings of desperately catching snippets of time for research, and waiting patiently to enjoy the spoils of labour like an addict waiting for the next 'high' (Hey, 2004).

An achievement focused academic life sits on the cusp of 'arrival.' After achieving tenure, I thought I had finally 'arrived' at my destination, but when the dust settled, I realised that my journey had only just begun. This was troubling as I had come to equate 'arriving' with a sense of wholeness and satisfaction. Carpenter relates this unique human experience in which "Time impatiently leads the way waiting for identity to catch up" and of ". . always becoming, never arriv[ing]." She describes the feeling of waiting for the next stage in life, a feeling she has had ever since she was a child, disclosing:

And so, throughout my life, anticipation of the next age stage of life kept me looking forward to improvements in my world. Each stage promised a new mosaic of identities and ways of being: child-school student-party goer-teacher-wage earner-adventurer-lover-partner-house owneruniversity lecturer-researcher-writer (emerald \& Carpenter, 2011, p. 1142).

An accelerated academic narrative revolves around the past as old work is recycled to increase publication output. There is also constant forward planning and multi-tasking to ensure that next year's research quota is met. Attention is inevitably split in different directions and knowledge becomes 'sufficient,' rather than rich or nuanced as focused attention becomes a luxury. There is also a sense of an unappreciated present as meaning is projected onto future events. Not only is success measured according to mastering life's milestones, progress is determined by whether we are on par with our colleague's achievements and the natural cycle or pace of life is dictated by the academic calendar, where "... moments of our being cannot help but be grounded in the academic moments providing time's measure" (Hendricks, 2008, p. 109). This objectifying and quantifying lens can lead to the "disenchantment" of "ritualistic performance, social conformity, group incohesion, dissolution/ meaninglessness, disengagement/resignation, hopelessness, dissipation, mindless consumption" (Hendricks, 2008, p. 109). Life becomes devoid of mystery as knowledge "... operates on laws and regularities discoverable through [rigid] naturalistic and scientific observation," and as a result, ". . all-natural phenomena are manifested as a function of these laws and regularities" and lose their sense of magic (Lee, 2009, p. 394). As academia rewards external, instrumental and measurable work, logic, we may lose the capacity to invoke personal desire or to engage in pleasurable work.

\section{The fear of the 'end' can lead to a workaholic life}


Time's passage becomes increasingly visible as the body slows. Marujo acknowledges how "physical changes" teach her that she can no longer live life as if it would go on forever (d'Araújo, Alpuim, CaRivero \& Marujo, 2016). The aging process brings the body's time clock to the surface, but it is possible to ignore passing time by distracting ourselves with an endless stream of instrumental tasks. Boje reflects on the fear of death that drives his workaholism, relating his work-obsessed father's belief that he would 'die' when he stopped working; this leads him to think that "You are worthless without your work. You will die without your work. There is nothing after work" (Boje \& Tyler, 2009, p. 179). I sensed a similar narrative from my mother who would tell the story of the diligent ants and the lazy crickets. The crickets starved to death as they failed to store food for the lean winter months, whilst the hardworking ants had plentiful food to enjoy. This message instilled a strong sense of fear of never having 'enough;' it resonated with the deficit perspective driving an accelerated and instrumental academic life of endless conquest and acquisition. The dominant narrative of academia was that no matter how much you have achieved, it could never satisfy.

This narrative of endless activity can be comforting as a highly structured and workaholic existence can provide a brief reprieve from existential concerns. Frentz (2011) discloses how his "old routine-driven lifestyle" helped him to forget his mortality after his beloved wife's death, "clutch[ing] at everything left in my life as barriers against aging and death" (p.802). Retirement, however, constructs a 'symbolic' death and brings his mortality to the forefront. Frentz illustrates the dilemma of unregulated and non-scheduled time, which is difficult to account for and harder to track and quantify. Such free time generates greater awareness of time's rapid flow and triggers a sense of urgency about increasingly limited time. Carpenter reflects on how the "spectre of mortality" becomes visible through "unbounded" time, as she states, ". . now I understand that mortality makes life matter. . . time is running out for me" (elke \& Carpenter, 2011, p. 1145). Frentz (2011) voices a similar realisation, stating, "I feel as if I don't have much time left-either in my calling, in my life, or even with my body and mind still in reasonably good shape;" he feels that he cannot "afford to rest for even one second or some form of death will overtake me" (p.803). He demonstrates how finitude, fragility and uncertainty is foregrounded when we sense time is running out. Uncertainty is considered to be a part of the human condition as the past is "hidden," the future is "evasive" and the present can evoke ".. such insecurity that it threatens our very autonomy" (Rentsch, 1997, p.267).

\section{Exploring new longings and finding desire}

Reflexivity interrupts a mindless and automatic existence by creating critical spaces to question the status quo and to consider "multiple meanings and numerous opportunities for choice, autonomy, self-expression, and pleasure" (Gilleard \& Higgs, 2010, p. 126). New and valuable discoveries can be made as individuals become open to alternate paths to follow. Retirement frees individuals from the obligations of paid employment and creates reflexive spaces rediscover 'personal' interests. In their study on academics' experience of time, Ylijoki and Mantyla (2003) introduce the notion of 'personal time,' which becomes visible in light of mortality or "the inescapable finitude of human existence- in the cycle of birth and death" (p.67). They argue that the narrative of a "good life" can be understood through a temporal lens, as the rewards for personally meaningful work are immediately received as the work itself is personally satisfying, whilst those for extrinsically motivated work are received 'after' the work is finished (Maclntyre, 1981). Personal time holds intrinsic meaning as rewards are received in present time.

A sense of limited time can sharpen focus and intensify experience, which can alert individuals to what holds 'true' value. Thomas (1995) argues that individuals cannot experience life to its fullest capacity unless they can confront their death. He argues that a "Being-toward-death" is the true human condition as it prevents us from "liv[ing] inauthentically, to live in bad faith" by conforming to external measures (p.298). Clarity develops through the backdrop of mortality, as Kotre (1984) writes, "In the chill of death, dew forms on the web of significance on which we collectively live our lives and for a time reveals its outline" (p. 269). The end reveals the preciousness of time, and can help us to better appreciate and live in the present moment. Richardson describes this real and intense phase in life where everything is felt acutely and in abundance 
(Ellis et al., 2017). She explains how everything becomes visceral as moments are experienced intensely, stating:

Post-university is for me more of everything: more deaths, more dying, more friends dying, more illness around me, more people being physically disabled, more stress on me to take care of people who are not well, and more fun, more grandchildren, more kinds of food, more of not caring what you're wearing, more laughter, more writing, more pleasure, more me (Ellis et al., 2017, p. 577).

New longings become visible as focus sharpens. LR reflects on how retirement has created spaces to discover new longings and to remember what she had previously longed for, explaining, "I think as we age, we know we can't long for some of the things we did long for. For me, it just opened up the question of what might I have longed for, what did I long for, what am I longing for?" (Ellis et al., 2017, p. 584). Some retirees rediscover what had inspired them to join academia (Davis \& Bansel, 2005), whilst others reconnect to childhood activities that gave great pleasure (Ellis et al., 2017). The open spaces generated in retirement can spark such personally meaningful explorations. Carpenter reflects on how the lack of a schedule creates fluid spaces to uncover longing and desire, writing, "The lack of time boundaries free me to develop a mindfulness of who I am and who I will become-to lean into the future and become less of a hostage to the tug of the past" (emerald \& Carpenter, 2011, p. 1145).

Freed from heavy, exhausting and endlessly critical work of academia, retirement can become a source of "unburdening lightness" (Davis \& Jenkins, 2013, p. 13). Pelias expresses this desire for 'lightness' as he finds himself nodding off while reading a PhD dissertation, as he seeks refuge from ". . another document that I must mark that I must judge. I feel the weight of the critical enterprise, the never-ending assessment. . . the critical life produces a culture of broken bones" (2016, p. 28). There is lightness in enjoying an activity purely for its own sake. Tyler equally yearns for more intrinsically meaningful goals, as opposed the critical enterprise of the academy, which she depicts, "[to be] a strenuous path, so the opposite of workaholism is not idleness" (Boje \& Tyler, 2011, p. 184). An awareness of time passing or limited time can remind academics that there is little time to get lost in "the woods" and to be weighed down by the institutions critical enterprise (Ellis et al., 2017).

Since fixed, instrumental and positivist spaces can suppress the personal desire, rediscovering desire requires open and expansive spaces for exploration. Desire is construed as a form of agency, as it can drive individuals to encounter, experience and feel deeply on their own accord. It evokes a vibrancy and richness that amplifies personal meaning. Dowd (2012) refers to desire as the will to "possess, consume, or achieve" or a form of "being in the world," that "enhance[s] one's interactions with others or to the successful accomplishment of one's project and goals" (p.287). Gerontology literature further describes desire as an "expanded level of competence," as opposed to "basic competence," which refers to the capacity for physical self-care. Desire extends beyond the satisfaction of basic needs to sustain life; it encompasses "the capacity of aging individuals to actively construct their lives through continued engagement in leisure activities, social relationships, helping others, and work" (Dowd, 2012, p.290). Expanded competence regards desire as an expression of one's personal energy and zest for life, which enables retirees to thrive through engaging in "self-realising projects" that projects them into the world. Retirees who exercise expanded competence can experience greater well-being during a time associated with alienation and diminishing capabilities (Dowd, 2012, p. 287).

\section{Generative work and desire}

Expanded competence encompasses a generative view of identity, as the self continues to be engaged and expressed through creative work. Generativity implies the continuation of meaning and influence through an activity that extends beyond the present time. Retirees who engage in generative work or 'self-realising' projects may develop cultural artefacts that can be passed down onto others (Kotre, 1984). Their work is generative, rather than simply creative, as it does not end when an activity is completed, or a product is 
made. Instead, the product develops with the creator who continues to engage with, care for and grow alongside their creation (Medeiros, 2009). Generativity subsequently facilitates a "self-repair" that counteracts the suffering caused by aging through "restor[ing] or repair[ing] a self in flux" (Medeiros, 2009). Medeiros (2009) illustrates this act of generativity through the case study of an 85-year-old man who uses wood working and poetry to make sense of his existential suffering. This man creates "unique, interactive and tangible entities" such as his wooden artefacts and poems, which allow him to "stave off threats to self and to create a sense of permanence ... [of his] fading life" (p. 97). He explores his evolving thoughts about self and life with the people who marvel at his wood carvings or listen to his poems. These conversations become generative and restorative as they allow him to tend to his creations, which are infused with his sense of self. The meaning that others derive from his work continues to enrich his sense of being in the world.

Retirement can create expansive spaces for generative work. In their paper Considering and Enjoying Tomorrow: Global Aging Through a Human Becoming Lens, Baumann and Soderhamn (2005) depict aging as a rich period of development and learning rather than decay. They discuss Parse's model of human becoming (Parse, 1998) to frame retirement as a "philosophy of living our aging" (p. 353). Baumann and Soderhamn (2005) propose that people can create a positive future through openness to the unknown, a sense of courage and the capacity for imagination "to cocreate change consistent with their cherished values and beliefs" and to create beauty within the difficult circumstances of the "not-yet" (pp. 354-356). As a midcareer academic, I seek to enhance my capacity for imagination and reflection through generative forms of creative inquiry that refreshes and renews. Andrews (2018) refers to imagination as means for inquiring into a sense of becoming and all its possibilities, as we she states:

Imagination is the mechanism which allows us to engage in a study of our own becoming, across the life cycle, to review the lives we have lived, to contemplate how they might have been different, to evaluate actions we did and did not take, to regard the present as but one pos-sibility of where the path might have led, and ultimately, to construct in our minds' eye a sense of what the future might hold, and aid us as we seek to embrace or avoid the realization of that vision (Andrews, 2018, p. 90).

She questions why people do not engage in these acts of imagination that can enhances the "potential of our future lives" through reading the stories of retirees that reveal the spectrum of possibilities for living well.

This theory of becoming presents aging as generative rather than a stagnant process, as even the losses incurred can lead to growth and a renewed appreciation for life. Through a rich theory of human becoming, retirees continually engage in the generative work of unravelling the puzzles of living, which " ... never settle, never feel resolved, fixed" so that you can be " . . kind of person [you] want to be, reflexive, pushed to [your] capacities, privileged to be with scholars, thinking and feeling [your] way, demanding daily more and more of [yourselves]" (Pelias, 2016, p.26). Randall (1999) describes such generative work as building a meaningful life story, where we "formulate (compose, narrate) and to follow (understand, read) the story of our own life" to "maneuver meaningfully through time" (pp. 13-14). Generative work is not separate from ourselves and enables our theories to become "applicable first and foremost to us" (Hendricks, 2008, p.113). Randall (2008) highlights how this process of 'becoming' allows us to establish a robust, "flexible, expansive, dynamic" narrative of self that allows us to "grow through" the changes brought on by passing time. Such a narrative may help us to imagine new meaningful possibilities outside of academia's accelerated path and beyond academia itself.

\section{Generative writing in post-retirement}

Generative writing can help academics engage in inquiry as 'self-realisng' projects. Such writing is infused with the self as it contains the author's personal voice. Generative writing speaks from the personal voice of the writer and enables the personal and professional to harmonise. In Clothing, aging and me-Routes to research, Twigg (2008) expresses her desire through personally authentic forms of writing. She acknowledges that she had never being able to successfully reconcile her personal passions with her academic work, despite 
always having been interested in the lived experience. She is, however, able to find the spaces to integrate an aesthetic and personal dimension through a conference paper that draws on her art history work. Her writing becomes richly textured as she reveals, "It is hard to convey the sheer pleasure of reviewing and scanning in those art history images- close ups of superb drapery, rich silks, sumptuous folds, vaporous gauzes - the joy of colour, surface, and the wonderful materiality of textiles" (p.160). Although her study relates to sociology rather than fashion, the topic of dress as a social phenomenon allows her to explore its aesthetic potential. She also writes in personally meaningful ways through exploring her own dilemmas about what to wear as she approaches her sixties. Twigg (2008) questions whether such writing marks a phase in her development, where her academic theorising is grounded in her own life.

Retired academics may increasingly move from "traditional or conventional modes to [more liberating] approaches that are more experimental or flexible or even looser" as they attempt to integrate the personal with the professional (Badley, 2016, p. 383). Frentz (2011) demonstrates similar experimentations with alternative writing styles and teaching, as he reflects, "I've also learned that I can forestall this symbolic death of retirement by continuing my academic calling through more experimental forms of writing and different varieties of non-academic teaching" (p.802). He reconciles the contradictory poles of his "theoretical and critical" work and his personal voice through experimentations with autoethnographic writing (p.801). This longing to voice what has been kept hidden is expressed by Carpenter, who reveals how she now writes, ". . . to give[s] voice to the many silenced thoughts and concerns that have been successfully crushed in the haste to commodify learning" to develop more nuanced understandings in her retirement (emerald \& Carpenter, 2011, p. 1145). In his work at the senior centre, Manheimer (2008) also uncovers how this emancipatory learning can be acquired later in life as his elderly participants tell their stories and read great works of philosophy and literature "to emancipate themselves from internalized attitudes of social marginality and obsolescence:" (p. 179).

Autoethnographic writing is one form of generative writing that can help academics increase their capacity for reflexivity. Autoethnography is a methodology of interpreting ("graphy") meaning from personal experiences ("auto") that convey important understanding about the broader culture ("ethno") (Bochner \& Ellis, 2006). Autoethnography integrates the autobiographical and ethnographic writing, as past encounters and memories are used to construct a narrative (Adams \& Ellis, 2017). Knowledge and inquiry is accordingly presented as intimate understandings of phenomena rather than as measurable and quantifiable facts (Ellis, Adams \& Bochner, 2010). In other words, autoethnographers write about everyday experiences that are difficult to capture through more traditional modes of research (Adams \& Ellis, 2017). Autoethnographic writing also enhances a researcher's capacity for critical reflexivity, as reflexivity is cultivated as researchers inquire into their lived experiences. Autoethnographies subsequently provides insight into the different cultural lives that may not be accessible to others (Adams \& Ellis, 2017). The focus on the "auto" also allows for writing styles that are more personal and creative, which makes the content more accessible to broader audiences, including those outside of the academic setting (Ellis et al., 2010). This integration of the "auto" and "ethno" is considered to be a fundamental of the aging process, as Manheimer (2008) writes:

If autobiography is an inescapable aspect of our participation in the aging field, then it's not surprising that personal and public history may intertwine. In more than most fields, we theorists of aging have an opportunity to see history in ourselves. Perhaps this is why, sometime in midlife, we may acquire bifocals, lenses that enable us to shift perspective between the near and far and, by analogy, the closely personal and the more comprehensively general (p. 180).

And finally, it may be easier for academics in qualitative rather than quantitative research fields to engage in generative and creative work in retirement. For example, activist academics can develop capacities for critical thinking, narrative imagination or empathetic awareness and an appreciation of diversity as they advocate on the behalf of others through their professional work (Yerbury \& Burridge, 2013; Nussbaum, 2009). They may be better equipped with the critically reflexive capacity to resist the dominant discourses that conflict with 
their inner beliefs and values, to make " ... the decisions about actions that will make the world in which we live better for us; as we do so, the wider society also benefits," and rather than being motivated purely by ambition, activist professionals are driven by more altruistic motivations (Yerbury \& Burridge, 2013, p. 123). Yerbury and Burridge found that academics who engaged in activism were also better at adjusting to life outside of the academy (Yerbury, H. \& Burridge, N. personal communication, June 21, 2019). These retirees experienced less hardship in letting go of their prestigious professional identity, as they were driven by a deep conviction in justice and equity as rather than extrinsic rewards and accolades. They were also deeply passionate about activism and continued on with such work during post-retirement. This continuation of identity, intrinsic meaning and purpose was also expressed by an academic in the Faculty of Creative Writing, who identified first and foremost as a creative writer (Adelaide, D. personal communication, Nov 14, 2019). Her creative writing work constructed the core of her personal identity and would subsequently continue fluidly into retirement, as she declares, "A writer never retires" (Adelaide, D. personal communication, Nov 14, 2019).

\section{Conclusion}

"A life is a work of art, probably the greatest one we produce. It is not simply art in the living. . [but in the telling- the telling after the fact to ourselves and others" (Bruner, 1995, p. 7).

My curiosity about retirement often draws attention. "What draws you to this topic?" people ask, gazing at dark hair and unlined face. In my more reflexive moments, I realise that my interest comes from a sense that the years will flow by quickly and predictably, filled with the busy work of accumulating achievements. A few questions are emerging, such as What will happen to this work? Who will use it? What will I do with it after I retire? Boje attempts to answer these questions by explaining the futility of hoarding grain that we cannot keep, stating, "You cannot take it with you. All the accumulation of success, in my case publications, conferences, awards, accomplishments, even helping others to succeed- cannot pass through death to the next life" (Boje \& Tyler, 2009, p. 184). My senior colleague, who was contemplating retirement, knew that he couldn't take his successes into this final stage of life. With this realisation in mind, I ask what would happen if I was to choose the life of a grasshopper over the toil of the ant, who is willing to "relish life in the present" (Mitchell \& Helson, 2016, p.214)? The grasshopper's life is a counter story to academia's accelerated narrative. It urges us to linger in the present moment and to embrace the 'unburdening lightness' of pleasurable work; it reminds us to seek open and contemplative spaces to cultivate the personal desire that is essential to living a meaningful life. My key tool for attaining such imaginative, reflexive and adaptive capacities is therefore generative and autoethnographic writing.

So, if not a lifetime of seeking achievement, what else awaits? I have attempted to address this question through this article by crafting my words so they paint a portrait of who I am as an academic writer. By using words to depict rather than to critique, I have aimed to embody the principle of "slow" in my writing. For me, such writing appears "timeless" as my mind is not harassed or harried by instrumental purposes; my words are poetic rather than analytical. I can find pleasure as I read and write my way into new creative and beautiful places (Yoo, 2017, p. 198).

As we experiment with academic work that is generative by evoking conversation in others, our writing may embody a sense of timelessness, "immanence" or an "un-interrupted" flow of breaths that enable "becoming and changing" (Heln, 2019, pp. 2-6). This notion of crafting timeless artefacts expressed in The Tale of Genji, where the author describes two types of wood-carvers. One type is seen to fashion toys according to society's current tastes, whilst the other seeks to create toys that are timeless in beauty and use. The author explains how idle work of the first should not be confused with these timeless masterpieces that outlives passing fads and fashions. Generative writing embodies the same qualities as the second toy maker's creations, which are formed from a more lasting substance. Such work may leave an indelible mark "stamped by the minter's die, creating a permanent artifact that can last for millennia" (Thomas, 1995, p.23), as it lives 
on in the minds of others, as Kotre (1995) remarks, ". . . it's about the seed a plant has produced rather than the fate of the plant as it lies withering on the ground" (p.34). These seeds carry the conversation forward and enable the seed-bearer's ideas to live on in others. The seed-bearer may attain an "'ageless' self that not only continually evolves and adapts," but "remains ageless even in the face of great change" (Kaufman, 1986, as cited in Medeiros, 2009, p. 98). Retirees can offer abundant potential to enrich the 'conversation' as they have accumulated a wealth of knowledge and insight through their career, "[as] their increasingly fertile inner substance matched by their capacity to articulate the insights it sprouts . . . [and] their inner-story world does not cease expansion nor do their interpretive talents diminish" (Randall, 1999, p.21). These stories can reveal what it means to live a rich academic career through renewal, discovery and growth.

\section{References}

Adams, T., Ellis, C., \& Holman Jones, S. (2017). Autoethnography: Understanding Qualitative Research. London: Oxford University Press.

Andrews, M. (2018). Imagining the 'baffling geography' of age. Journal of Aging Studies, 47(1), 90- 95.

Badley, G. F. (2016). Composing Academic Identities: Stories That Matter? Qualitative Inquiry, 22(5), $377-385$. doi: $10.1177 / 1077800415615845$

Baumann, S. L., \& Soderhamn, O. (2005). Considering and Enjoying Tomorrow: Global Aging Through a Human Becoming Lens. Nursing Science Quarterly, 18(4), 353-358. doi: 10.1177/0894318405280373

Bochner, A. P., \& Ellis, C. S. (2006). Communication as autoethnography. In G. J. Shepherd, J. St. John, \& T. Striphas (Eds.), Communication as ... Perspectives on theory (pp. 110-122). Thousand Oaks, CA: SAGE.

Boje, D., \& Tyler, Jo. A. (2009). Story and Narrative Noticing: Workaholism Autoethnographies. Journal of Business Ethics. 84(2), 173-194. doi:10.1007/s10551-008-9702-7

Bruner, J. (1995). Narratives of Aging. Journal of Aging Studies, 13(1), 7-9.

Cruikshank, M. (2008). Aging and Identity Politics. Journal of Aging Studies, 22(2), 147-151.

doi:10.1016/j.jaging.2007.12.011

d’Araújo, M.A., Alpuim, M., River, C., \& Marujo, H. Á. (2016). Narrative Practices and Positive Aging: A Reflection about Life Celebration in a Group of Old Women, Women \& Therapy, 39(1-2), 106-123. doi:10.1080/02703149.2016.1116323

Davis, B. \& Bansel, P. (2005). The Time of their Lives? Academic Workers in Neoliberal Time(s). Health Sociology Review. 14(1), 47-58.

Davis, E., \& Jenkins, A. (2013). The Work-to-Retirement Transition of Academic Staff: Attitudes and Experiences. Employee Relations, 35(3), 322-338.

Dowd, J. J. (2012). Aging and the Course of Desire. Journal of Aging Studies, 26(3), 285-295. doi:10.1016/j.jaging.2007.12.011

Ellis et al. (2017). Living the Post-University Life: Academics Talk About Retirement. Qualitative Inquiry. 23(8), 575-588.

Ellis, C. (2011). "Jumping On and Off the Runaway Train of Success: Stress and Committed Intensity in an Academic Life." Symbolic Interaction. 34(2), 158-173. doi: 10.1525/si.2011.34.2.158 
Ellis, Carolyn, Adams, Tony E. \& Bochner, Arthur P. (2010). Autoethnography: An Overview [40 paragraphs]. Forum Qualitative Sozialforschung / Forum: Qualitative Social Research, 12(1), Art. 10, http://nbnresolving.de/urn:nbn:de:0114-fqs1101108.

emerald, e., \& Carpenter, L., (2014). The Scholar Retires: An Embodied Identity Journey. Qualitative Inquiry, 20(10), 1141-1147. doi: 10.1177/1077800414545232

Frentz, T. (2011). Is It Time Yet? Qualitative Inquiry. 17(9). 798-804. doi: 10.1177/1077800411423195

Grant, B. M. (2019). Wrestling with Career: An Autoethnographic Tale of a Cracked Self. In Bottrell, D., \& Manathunga, C. (Eds.). Resisting Neoliberalism in Higher Education Volume I Seeing Through the Cracks. (pp. 119-134). New York: Palgrave Macmillan US.

Heln, S. F. (2019). Deleuze, immanence, and immanent writing in qualitative inquiry: Nonlinear texts and being a traitor to writing. Qualitative Inquiry, 25, 83-90. doi:10.1177 /1077800418784328

Hendricks, J. (2008). Coming of Age. Journal of Aging Studies, 22(2), 109-114.

doi:10.1016/j.jaging.2007.12.015

Hendricks, J. (1992). Learning to Act Old: Heroes, Villains or Old Fools. Journal of Aging Studies, 6(1), 1-11.

Hey, V. (2004). Perverse Pleasures - Identity Work and the Paradoxes of Greedy Institutions. Journal of International Women's Studies, 5(3), 33-43.

Immanent. (n.d.). Retrieved from https://www.merriam-webster. com/dictionary/immanent

Kaufman, S. (1986). The ageless self: Sources of Meaning in Late Life. Madison, WI: The University of Wisconsin Press.

Kotre, J. (1995). Generative Outcome. Journal of Aging Studies, 9(1), 33-41.

Kotre, J. (1984). Outliving the self: Generativity and the Interpretation of Lives. Baltimore: The Johns Hopkins University Press.

Keneally, Thomas Sat $11^{\text {th }}$ Nov 2018 Guardian Thomas Keneally: Death is not the fly in the cosmic ointment. It is the cosmic ointment. Retrieved from https://www.theguardian.com/books/2017/nov/11/thomas-keneallydeath-is-not-the-fly-in-the-cosmic-ointment-it-is-the-cosmic-ointment 20th 11 Nov

MacIntyre, A. (1981). After Virtue: A study in Moral Theory. Notre Dame: University of Notre Dame Press.

Manheimer, R.J. Becoming historial to oneself. Journal of Aging Studies, 2(22), 177-183.

doi:10.1016/j.jaging.2007.12.0086

Medeiros, K. D. (2009). Suffering and Generativity: Repairing Threats to Self in Old Age. Journal of Aging Studies. 23(2), 97-102.

Mitchell, V., \& Helson, R. M. (2016). The Place of Purpose in Life in Women's Positive Aging, Women \& Therapy, 39(1-2), 213-234. doi:10.1080/02703149.2016.1116856

Nussbaum, M. (2009). Education for Profit, Education for Freedom. Liberal Education, 95 (3), 6-13. Retrieved from https://www.aacu.org/publications-research/periodicals/education-profit-education-freedom-0

Pelias, R. J. (2016). The End of an Academic Career: the Desperate Attempt to Hang on and Let go, Qualitative Inquiry, 22(1), 25-29. doi: 10.1177/1077800415603398

Randall, W. L. (2008). Getting my Stories Straight: a Narrativist in Quest of Congruence. Journal of Aging Studies, 2(22), 169-176. doi:10.1016/j.jaging.2007.12.008 
Richardson, L. (2014). Fear of Falling. Qualitative Inquiry, 20(10), 1133-1140. doi:

$10.1177 / 1077800414543697$

Robertson, R., \& Hetherington, P. (2017). A mosaic patterning: Space, time and the lyric essay. New Writing: The International Journal for the Practice and Theory of Creative Writing, 14(1), 36-46.

Shahjahan, R. A. (2015). Being 'Lazy' and Slowing Down: Toward Decolonising Time, our Body and Pedagogy. Educational Philosophy and Theory, 47(5), 488-501.

Thomas, E. L. (1995). Conflicting Time Perspectives in Academic Work. Journal of Aging Studies. 9(1), 21-31.

Twigg, J. (2008). Clothing, Aging and Me- Routes to Research. Journal of Aging Studies. 22(2), 158-162. doi:10.1016/j.jaging.2007.12.010

Ylijoki, O. H. \& Mantyla, H. (2003). Conflicting Time Perspectives in Academic Work. Time \& Society. 12(1), 5578.

Yerbury, H., \& Burridge, N. (2013). The activist professional: Advocacy and scholarship. Third Sector Review, 19(2), 119-134. Retrieved from https://search.informit.org/documentSummary;res=IELAPA; dn=855423633041918

Yoo, J. (2019). Learning to Write Through an Awareness of Breath. Qualitative Inquiry. Advance online publication. https://doi-org.ezproxy.lib.uts.edu.au/10.1177/1077800419846533

Yoo, J. (2019). Learning to Write Through an Awareness of Breath. Qualitative Inquiry, 25(2), 192-199. doi: $10.1177 / 1077800417745102$ 